\title{
Determinants of Neonatal Mortality in Kenya: Evidence From Kenya Demographic Health Surveys, 2008 and 2014
}

\author{
Elizabeth Imbo ${ }^{1} \quad$ Dr Elizabeth Kamau-Mbuthia ${ }^{1} \quad$ Dr Dougla Ngotho ${ }^{2}$ \\ 1.Department of human Nutrition and Dietetics Egerton University P.O Box 536-20115, Egerton, Kenya \\ 2.Department of Medicine and Surgery Egerton University P.O Box 536-20115, Egerton, Kenya
}

\begin{abstract}
Background: This paper analyses the contribution of socio demographic, neonatal, maternal and health facility related factors to the neonatal mortality in Kenya. Methods: Data from the Kenya demographic and health survey 2008 and 2014 was analyzed. Results: Logistic regression showed that in 2008, newborns with a short interval of $<2$ years $(\mathrm{OR}=1.938, \mathrm{p}=0.000)$, very small babies, $(\mathrm{OR} 2.25, \mathrm{p}=0.160)$, low birth weight $(\mathrm{OR}=6.677, \mathrm{p}=0.000)$, male children $(\mathrm{OR}=1.243, \mathrm{p}=0.028)$ and neonates not breastfed immediately after birth $(\mathrm{OR}=2.768, \mathrm{p}=0.005)$ increased the risk of mortality. In 2014 , being born in urban areas $(\mathrm{OR}=1.323, \mathrm{p}=0.028)$, low birth weight $(\mathrm{OR}=2.354, \mathrm{p}=0.008)$, birth interval of $<2$ years $(\mathrm{OR}=1.549, \mathrm{p}=0.028$, boys $(\mathrm{OR}=1.443,0.014)$, mothers who did not attend ANC and those who had $<3$ ANC visits had $(\mathrm{OR}=4.668, \mathrm{p}=0.000)$ and $(\mathrm{OR}=1.572, \mathrm{p}=0.003)$ respectively as associated with neonatal mortality. Conclusion: This paper emphasizes on mother nutrition education, immediate initiation of breast feeding, attending $4 \mathrm{ANC}$ and hospital delivery for better birth outcomes. Key words: Determinants, Neonatal, Mortality, logistic regression, breastfeeding, birth weight

DOI: $10.7176 / \mathrm{JHMN} / 65-06$
\end{abstract}

Publication date: August $31^{\text {st }} 2019$

\section{Background}

Neonatal mortality remains a significant public health problem worldwide and accounts for $60 \%$ of the newborn deaths in the middle and lower income countries (UNICEF,2017). This is because the neonatal period is considered as the most vulnerable time for a child's survival. Globally, 18 children out of every 1000 live births. In 2017 alone, 2.5 million children died in the first month of life in 2017 alone (UNICEF, 2017). Of these deaths, approximately 1,000,000 die within the first week of life. Decline in neonatal has been realized globally, but this decline is slower compared to mortality among children between 1-11 months and those 1- 4 years. The neonatal mortality rates fell by $51 \%$ from 37 deaths per 1000 live births in 1990 to the current 18 deaths per 1000 live births in 2017 a small reduction compared to the other groups.

Despite the global reduction in the neonatal mortality, disparities exist in across the regions. Neonatal mortality is highest in in sub Saharan Africa (SSA) and in South Asia (SA) each with an estimated Neonatal Mortality Rate (NMR) of 27 per 1000 live births, and children born in these two regions are nine times more likely to die in their first month of life than a child born in a high income country. More than $50 \%$ of under-five Mortality rates (U5MR) occur in the neonatal period. In Aouth Asia, the proportion of children dying in the neonatal period is higher at $60 \%$ of the total U5MR.

These statistics makes neonatal mortality an important public health concern which have been prioritized under the Sustainable Development Goals (SDGs) previously referred to as the Millennium Development Goals (MDGs). In Kenya, the neonatal mortality rate is 22 deaths per 1000 live births with the urban areas having a higher NMR of 26 per 1000 live births compared to 21 deaths per 1000 live births in the rural areas. (UNICEF, 2015)

Although Kenya has made positive progress in the overall childhood indicators over time, the country continues to train in the neonatal mortality indicators which have only marginally reduced from 33/1000 live births in 2003 (KNBS.2003) to 31/1000 live births in 2008/9 (KNBS.2009) and 22 deaths per 1000 live births in 2014 (KNBS.2014). Studies in several countries have shown that neonatal mortality results from a complex chain of biological, socio economic, demographic and health care related determinants. However common causes of neonatal mortality include birth asphyxia, pre-term birth complications, intra partum related factors, infections such as pneumonia and tetanus, low birth weight congenital malformations and neonatal sepsis (Jehan et al, 2008; Khatun et al, 2012; WHO. 2011). There exists a relationship between maternal health and neonatal survival. Poor maternal nutritional and health status has been related to poor birth outcomes and this is influenced by elements such as socio economic, demographic and biological factors. The low uptake of contraceptives by women in reproductive age, especially those from the rural areas, advances the explanation that unplanned pregnancies and increased parity which research has shown are important risk factors to neonatal survival. Consequently, the intricate relationship between the mothers' health and that of the neonate's means that measures like the essential ante natal care (ANC), access to emergency obstetric care, access to skilled attendance at birth, adequate nutrition, post-partum care, neonatal care and early initiation of breastfeeding if adequately implemented can ensure neonatal survival. 
The main goal of this study was to determine the trends and determinants of neonatal mortality using the KDHS data of 2008 and 2014. The findings from this study would be useful for policy processes in both health and nutrition, designing and scaling interventions that will support reduction of neonatal mortality in Kenya.

\section{Objectives of the study}

i. $\quad$ To determine the neonatal mortality in households in Kenya under KDHS of 2008 and 2014.

ii. To determine the factors associated with neonatal mortality in households in Kenya under KDHS of 2008 and 2014.

\section{Literature review and theoretical framework}

Social-economic characteristics related to neonatal mortality.

The socio economic determines of neonatal mortality in this study have been defined through the levels of education, income and place of residence. Their measurement was used to assess proximate as expressed by Mosely and Chen (1984). These determinants help explain the underlying reasons though the theoretical framework to the causes of neonatal morality in Kenya.

\section{Maternal characteristics related to neonatal mortality.}

Maternal characteristics included age of the mother, age at first birth of the mother, highest level of education, preceding birth interval, Maternal BMI and breastfeeding practices. BMI was used to measure the mothers' nutritional status. The BMI cut offs were computed based on the WHO standards and were defined as $<18.5=$ underweight, 18.5-24.9 =normal and $>25.0$ as overweight.

\section{Neonatal characteristics.}

Neonatal characteristics included neonatal birth weight, birth size, sex of the child and birth order of the child and the preceding birth interval.

\section{Health facility characteristics.}

Health characteristics included use of antenatal clinic services and place of delivery. For uptake of ANC services, the cut of was based on the recommended minimum of 4 antenatal visits into two categories $<4$ ANC visits and $>4$ ANC visits. Place of delivery was categorized as health facility and home delivery.

\section{Conceptual framework}

The proposed conceptual framework for this study described the scope as derived from the analytical framework of Mosley and Chen (1984) on child survival. This framework for child survival is widely used in studies that have assessed determinants of neonatal mortality in several countries. The variables in the conceptual framework are grouped into socioeconomic characteristics (3 variables), neonatal characteristics (3 variables), health system characteristics (2variables) and maternal characteristics (4 variables).

This framework has been adjusted to capture the relationships of the variables under study and how they interact with the outcome variable. The selected variables are those that have been considered under the KDHS survey analysis. 


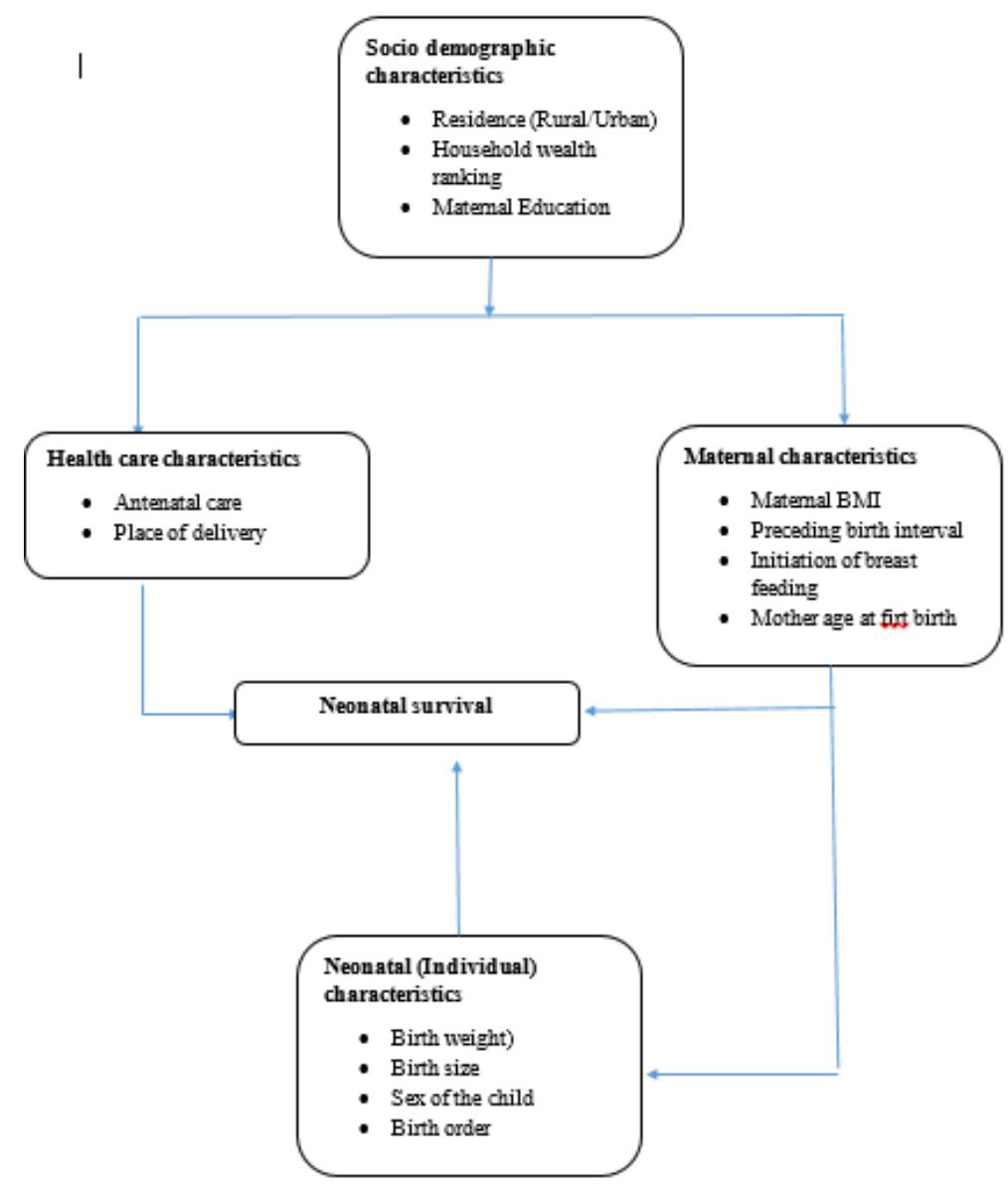

Figure 1: Conceptual framework developed for the study of determinants of neonatal mortality in Kenya.

\section{Methodology.}

The analysis used data from the KDHS of 2008/09 and KDHS 2014 survey data. The data is available to the public for use upon submission of request to utilize the data for analysis. Permission to use the data was obtained from ORC Macro International, the agency responsible for all the DHS data globally. The DHS uses a multi stage sampling methodology which samples households in selected clusters. Households are then systematically selected from the clustered and residents are eligible for to participate in the survey. In total 8,444 eligible women were administered with the interview, translating to a 93.6\% response rate in 2008. In 2014, 14,741 eligible women were interviewed which was a $96.2 \%$ response rate. Analysis included all live births in the last five years preceding the 2008 survey who totaled to 5852 . In 2014, the total live births were 19,565 . The total neonatal deaths in the 2008 KDHS was 183 where as in 2014, the neonatal deaths were 427.

Data was analyzed with SPSS statistical software version 20.0 Analysis was done at descriptive, univariate and multivariate levels. Bivariate analysis was used to check for association between neonatal, health facility and maternal characteristics on the neonatal deaths. Binary logistic regression was used to determine odds ratio for the association between social, biological neonatal and healthcare factors to neonatal mortality. The analysis was done using complex sample analysis to adjust for the cluster sampling design used in the KDHS.

The main outcome variable was neonatal deaths expressed in a binary form ( 0 dead and 1 alive). Neonatal mortality is defined as death before 28 days. Independent variables include demographic characteristics such as place of residence, wealth status, maternal characteristics such as maternal education, maternal age at first birth, maternal age, birth order, preceding birth interval, maternal BMI, commencement of breast feeding, neonatal characteristics such as size of the child, sex and birth weight of the child and health service characteristics including ANC visits and place of delivery. All statistical testing was done at $95 \%$ confidence interval.

\section{Results}

In the analysis of the background characteristics, we looked at the residence, wealth status, mothers level of education. A total of 25,417- live births within the 5 years preceding the 2008/09 and 2014 analysis were included in the analysis. The background characteristics are presented in table 1 (below)

The neonatal mortality in $2008 / 9$ as 22 per 1000 . There was a total of 5852 live births included in the study 
and 183 neonates died within the first 28 days Neonates born to mothers residing in the rural areas had a slightly lower NMR compared to their counterparts in the urban areas (NMR: 31vs 32) the poorest households had the highest NMR compared to the middle class households (NMR: 41 vs 37). Neonates whose mothers had no education had the highest NMR compared to those with primary education (NMR: 41 vs 27). Male neonates had higher NMR compared to females (NMR: 36 vs 25) respectively. Neonates whose mothers perceived them as small had a higher NMR of 89 compared to an average size child whose NMR was 24.

In 2014 DHS analysis the NMR in urban areas as higher compared to neonates born in the rural areas (NMR 25 vs 20). The 2014 KDHS however showed that poor households had lower NMR compared to the rich households (NMR: 20 vs 23). Neonates whose mothers had no education had the low NMR compare to mothers with higher levels of education (NMR: 20 vs 23).

Table 1: Distribution of household, maternal, health sector and neonatal related characteristics, KDHS 2008/09

\begin{tabular}{|c|c|c|c|c|c|c|c|}
\hline & & \multicolumn{3}{|c|}{ KDHS 2008-09 } & \multicolumn{3}{|c|}{ KDHS 2014} \\
\hline & & $\begin{array}{l}\text { Neonatal } \\
\text { deaths } \\
\mathrm{N}=\mathbf{1 8 3} \\
\end{array}$ & $\begin{array}{l}\text { Total live } \\
\text { births } \\
\mathrm{N}=\mathbf{5 8 5 2}\end{array}$ & NMR & $\begin{array}{l}\text { Neonatal } \\
\text { deaths } \\
\mathrm{N}=427 \\
\end{array}$ & $\begin{array}{l}\text { Total live } \\
\text { births } \\
\mathrm{N}=19565 \\
\end{array}$ & NMR \\
\hline \multirow[t]{2}{*}{ Residence } & Urban & 35 & 1074 & 32.5 & 176 & 7024 & 25 \\
\hline & Rural & 148 & 4777 & 31 & 251 & 12540 & 20 \\
\hline \multirow[t]{5}{*}{ Wealth status } & Poorest & 60 & 1445 & 41 & 95 & 4658 & 20 \\
\hline & Poor & 30 & 1190 & 25 & 80 & 3987 & 20 \\
\hline & Middle & 40 & 1085 & 37 & 80 & 3525 & 22 \\
\hline & Rich & 15 & 1038 & 14 & 82 & 3453 & 23 \\
\hline & Richest & 38 & 1095 & 34 & 91 & 3942 & 23 \\
\hline \multirow[t]{4}{*}{ Mothers education } & No education & 31 & 763 & 41 & 51 & 2308 & 22 \\
\hline & Primary & 101 & 3713 & 27 & 241 & 10979 & 21 \\
\hline & Secondary & 37 & 1105 & 33 & 82 & 4633 & 17 \\
\hline & higher & 14 & 271 & & 53 & 1645 & 32 \\
\hline \multicolumn{8}{|l|}{ Age at first birth } \\
\hline & Below 19 years & 88 & 3601 & 24 & 200 & 10873 & 18 \\
\hline & 20-29 years & 87 & 2209 & 39 & 216 & 8407 & 25 \\
\hline & $30-39$ years & 6 & 43 & & 11 & 275 & 40 \\
\hline \multirow[t]{3}{*}{ Birth Order } & First child & 42 & 1309 & 32 & 129 & 5104 & 25 \\
\hline & $2^{\text {nd }}$ or $3^{\text {rd }}$ child & 71 & 2225 & 31 & 145 & 7669 & 19 \\
\hline & $4^{\text {th }}$ and above & 70 & 2318 & 30 & 153 & 6791 & 22 \\
\hline \multirow{2}{*}{$\begin{array}{lr}\text { Birth } & \text { spacing } \\
\text { (preceding } & \text { birth } \\
\text { interval) } & \end{array}$} & $<2$ years & 53 & 1024 & 52 & 72 & 2570 & 28 \\
\hline & $>2$ years & 87 & 3507 & 24 & 209 & 11818 & 17 \\
\hline \multirow[t]{3}{*}{ BMI } & Underweight & 11 & 730 & 16.4 & 22 & 1082 & 20 \\
\hline & Normal weight & 125 & 3875 & 32 & 125 & 5412 & 23 \\
\hline & Overweight & 46 & 1178 & 39 & 64 & 2780 & 23 \\
\hline \multirow{3}{*}{$\begin{array}{l}\text { Time for } \\
\text { commencing } \\
\text { breastfeeding after } \\
\text { birth }\end{array}$} & Immediately & 13 & 22552160 & 5.76 & 26 & 3980 & 6 \\
\hline & $\begin{array}{l}\text { Between } 1 \text { hour } \\
\text { and } 24 \text { hours }\end{array}$ & 19 & 10981193 & 24.8 & 10 & 2283 & 4 \\
\hline & After 24 hours & 0 & 522 & & 6 & 512 & 11 \\
\hline \multicolumn{8}{|l|}{$\begin{array}{l}\text { Child } \\
\text { characteristics }\end{array}$} \\
\hline \multirow[t]{5}{*}{ Size of the child } & Very large & 7 & 302 & 23 & 9 & 305 & 29 \\
\hline & $\begin{array}{l}\text { Larger than } \\
\text { average }\end{array}$ & 51 & 1555 & 32 & 56 & 2085 & 26 \\
\hline & Average & 73 & 3006 & 24 & 71 & 5429 & 13 \\
\hline & $\begin{array}{l}\text { Smaller than } \\
\text { average }\end{array}$ & 25 & 748 & 33 & 40 & 1088 & 36 \\
\hline & Very small & 17 & 189 & 89 & 18 & 309 & 58 \\
\hline
\end{tabular}




\begin{tabular}{|c|c|c|c|c|c|c|c|}
\hline & & \multicolumn{3}{|c|}{ KDHS 2008-09 } & \multicolumn{3}{|c|}{ KDHS 2014} \\
\hline & & $\begin{array}{l}\text { Neonatal } \\
\text { deaths } \\
\mathbf{N}=\mathbf{1 8 3}\end{array}$ & $\begin{array}{l}\text { Total live } \\
\text { births } \\
\mathrm{N}=\mathbf{5 8 5 2}\end{array}$ & NMR & $\begin{array}{l}\text { Neonatal } \\
\text { deaths } \\
\mathbf{N}=427\end{array}$ & $\begin{array}{l}\text { Total live } \\
\text { births } \\
\mathrm{N}=19565\end{array}$ & NMR \\
\hline \multirow[t]{2}{*}{ Sex of the child } & Male & 110 & 3027 & 36 & 231 & 9937 & 23 \\
\hline & Female & 71 & 2825 & 25 & 196 & 9626 & 20 \\
\hline \multicolumn{8}{|l|}{ Birth weight } \\
\hline & Underweight & 17 & 153 & & 22 & 466 & 47 \\
\hline & Normal weight & 36 & 1773 & & 34 & 3211 & 10 \\
\hline & $\begin{array}{l}\text { Above average } \\
\text { weight }\end{array}$ & 17 & 803 & & 36 & 2469 & 26 \\
\hline & Not weighed & 207 & 3098 & & 111 & 3181 & \\
\hline $\begin{array}{l}\text { Health service } \\
\text { characteristics }\end{array}$ & & & & & & & \\
\hline \multirow[t]{2}{*}{ Place of delivery } & Facility & 86 & 3346 & 36 & 148 & 7308 & 20 \\
\hline & Home & 92 & 2493 & 25 & 255 & 11969 & 21 \\
\hline \multirow{3}{*}{$\begin{array}{l}\text { Number of ANC } \\
\text { visits }\end{array}$} & No ANC visits & 6 & 366 & 16 & 30 & 615 & 48.7 \\
\hline & 1-3 ANC visits & 23 & 1730 & 13 & 88 & 5505 & 15.9 \\
\hline & $>4$ ANC visits & 60 & 1872 & 32 & 89 & 8322 & 10.6 \\
\hline
\end{tabular}

\section{Bivariate analysis}

Cross tabulations were undertaken to establish if there existed associations between the dependent variable (neonatal morality) and the other independent variables. The chi square analysis showed some significant associations between the neonatal mortality variable and other independent variables. For the $2008 \mathrm{KDHS}$ analysis, these variables included mother's education $(2=8.112, \mathrm{p}=0.044)$, age of the mother at first birth $\left({ }^{2}=27.309\right.$, $\mathrm{p}=0.000)$, birth spacing ( $2=12.687, \mathrm{p}=0.000)$, mothers BMI $(2=7.383, \mathrm{p}=0.025)$, initiation of breast feeding ( $2=14.235, \mathrm{p}=0.001)$ size of the child $\left({ }^{2}=28.067, \mathrm{p}=0.000\right)$, birthweight of the child $(2=48.388, \mathrm{p}=0.000)$, sex of the child ( $2=6.066, \mathrm{p}=0.014)$, place of delivery $(2=6.064, \mathrm{p}=0.014)$ and the number of ANC visits by the mother ( $2=15.096, p=0.001$ ). Analysis for the 2014 KDHS findings, after the chi square analysis, there was an established association between neonatal mortality and place of residence $(2=5.355, \mathrm{p}=0.021)$, mothers' education $(2=12.027, \mathrm{p}=0.007)$ age at first birth $(2=16.120, \mathrm{p}=0.000)$, birth order $(2=6.055, \mathrm{p}=0.048)$, preceding birth interval $(2=11.765, \mathrm{p}=0.001)$, size of the infant $(2=55.007 . \mathrm{p}=0.000)$, birth weight $(2=64.827$, $\mathrm{p}=0.000$ and the number of antenatal visits $(2=60.486, \mathrm{p}=0.000)$. Table 2: Chi square analysis of characteristics associated with neonatal mortality, KDHS 2008 and 2014.

\begin{tabular}{|c|c|c|c|c|}
\hline \multirow[b]{2}{*}{ Variables } & \multicolumn{2}{|c|}{ KDHS 2008} & \multicolumn{2}{|c|}{ KDHS 2014} \\
\hline & $\chi^{2}$ & $P$ values & $\chi^{2}$ & $P$ values \\
\hline \multicolumn{5}{|l|}{ Demographic characteristics } \\
\hline Residence & 0.073 & 0.788 & 5.355 & $0.021 *$ \\
\hline Wealth status & 17.694 & $0.001 *$ & 2.026 & 0.731 \\
\hline \multicolumn{5}{|l|}{ Mothers characteristics } \\
\hline Mothers education & 8.112 & $0.044 \mathrm{~s}$ & 12.027 & $0.007 * *$ \\
\hline Age at first birth & 27.309 & $0.000 *$ & 16.120 & $0.000^{*}$ \\
\hline Birth Order & 0.146 & 0.929 & 6.055 & $0.048 *$ \\
\hline $\begin{array}{l}\text { Birth spacing (preceding birth } \\
\text { interval) }\end{array}$ & 12.687 & 0.000 & 11.765 & $0.001 *$ \\
\hline BMI & 7.383 & $0.025^{*}$ & 0.330 & 0.848 \\
\hline Initiation of breastfeeding & 14.235 & $0.000 *$ & 3.848 & 0.146 \\
\hline \multicolumn{5}{|l|}{ Child characteristics } \\
\hline Size of the child & 28.067 & $0.000 *$ & 55.007 & $0.000 *$ \\
\hline Sex of the child & 6.033 & $0.014^{*}$ & 1.909 & 0.167 \\
\hline Birth weight & 48.388 & $0.000 *$ & 64.827 & 0.000 \\
\hline \multicolumn{5}{|l|}{ Health service characteristics } \\
\hline Place of delivery & 6.064 & $0.014 *$ & 0.248 & 0.618 \\
\hline Number of ANC visits & 15.096 & $0.001 *$ & 60.486 & $0.000 *$ \\
\hline
\end{tabular}

Logistic regression analysis for neonatal mortality

To establish the determinants of neonatal mortality, the study used logistic regression by use of a simple univariate 
cox hazards regression ` using the formula below:

$$
\operatorname{logit}(p)=b_{0}+b_{1} X_{1}+b_{2} X_{2}+b_{3} X_{3}+\ldots+b_{k} X_{k}
$$

The binary logistic regression model shows the independent (adjusted) effects of the socio demographic characteristic on neonatal mortality. The results showed in the table 3 below show that infants born from the urban areas had higher odds of dying compared to those born in the rural areas (OR 1.323 p 0.028) in the2014 KDHS. The 2008 results did no show significant relationship. Children born of poor households showed a high risk of dying within the first month of life however, these findings were not statistically significant. The same trend was observed in 2014.

\section{Maternal characteristics.}

The model then analyzed the effects of maternal characteristics on the risk of neonatal deaths. The findings for both the 2008 and 2014 KDHS showed that infants born od mothers with low BMI had a lower risk of dying compare ho those with BMI above 25. These finds were inconsistent with existing literature on maternal BMI and the risk of neonatal mortality, where neonates born of mothers with low BMI had an increased risk of dying in the first month of life.

In regard to the preceding birth intervals, neonates born less than 2 years from the preceding birth had a higher odd of dying $(\mathrm{OR}=1.938, \mathrm{P}=0.000)$ compared to those born within an interval of above 2 years. This was according to the KDHS 2008 study findings. The 2014 analysis showed a similar trend, with children within 2 years of the previous having 1.5-times likelihood of dying compared to those born with more than 2 years' birth interval. These associations showed statistical significance for both study periods.

\section{Neonatal characteristics}

The model that was considered in the analysis of child characteristics in relation to the risk of neonatal morality. In this model, the child related characteristics i.e. size of the child, birth weight of the child, sex of the child and the birth order of the child were all fit into the logistic regression model. The findings showed that first born (children of the first order) had the highest risk of dying compared to $4^{\text {th }}$ order and above. This was true in both the analyses of 2008 and 2014, however, these findings did not show statistical significance $(\mathrm{OR}=1.775, \mathrm{p}=0.447$ and $\mathrm{OR}=1.412, \mathrm{p}=0.08$ ) respectively. Children who were considered very small by their mothers at the time of birth were 2 times more likely to die compare to larger children. The 2008 findings showed that $(\mathrm{OR}=2.015$, $\mathrm{p}=0.160$ ) and the 2014 findings were $\mathrm{OR}=1.523, \mathrm{p}=0.347)$. These findings were however not statistically significant. It was however noteworthy that children who were reported to be of average size at the time of birth in the 2014 KDHS study had the lowest risk of neonatal mortality with OR $0.446, p=0.031$. Male neonates are more likely (OR 1.423, $\mathrm{p}=0.028$ ) to die than female neonates in the first month of life. This was the case in the KDHS 2008 analysis. The scenario was similar in 2014 KDHS study with an OR 1.443, $\mathrm{p}=0.014$ ). These associations were found to be statistically significant. Children who were not weighed birth and those born with low birth weight had the higher odds of dying compared to those of normal birth weight. In the 2008 KDHS study findings, LBW children were 6 times more likely to die in the neonatal period compared to normal weight children $(\mathrm{OR}=6.677, \mathrm{p}=0.000)$. In 2014, LBW children were 2 times more likely to die $(\mathrm{OR}=2.354, \mathrm{p}=0.008)$. these associations were found to be statistically significant.

\section{Health care characteristics.}

The analysis of the DHS findings showed that children born at the health facilities were at higher odds of dying within the neonatal period. However, these associations were not found to be statistically significant. In the analysis of the KDHS 2014 neonates of mothers who had not attended any ANC visits had a higher risk of death $(\mathrm{OR}=4.668, \mathrm{p}=0.000)$ compared to mothers who attended more than 4 ANC visits. Similarly, mothers who attended between 0-3 ANC visits had 1.5 times more likely to lose their babes in the neonatal period compare to those who attended more than $4 \mathrm{ANC}$ visits $(\mathrm{OR}=1.572, \mathrm{p}=0.003)$.

Neonates who were not immediately initiated to breastfeeding in 2009 KDHS were more likely to die (OR 3.142 CI (1.536-6.428), $\mathrm{p}=0.001$ compared to neonates immediately initiated to breastmilk. A similar trend is also observed in 2014 with OR=2.496 CI 1.038-6.002 $\mathrm{p}=0.041$. 
Table 3: Logistic regression analysis of the determinants of neonatal mortality (adjusted Odds ratio) KDHS $2008 \_09$ and 2014.

\begin{tabular}{|c|c|c|c|c|c|c|c|}
\hline & & \multicolumn{3}{|c|}{ KDHS 2008_09 } & \multicolumn{3}{|c|}{ KDHS 2014} \\
\hline & & OR & $95 \% \mathrm{CI}$ & $P$ value & OR & $95 \%$ CI & $P$ value \\
\hline \multirow[t]{2}{*}{ Residence } & Urban & 1.126 & $0.615-2.061$ & 0.700 & 1.323 & $1.031-1.699$ & 0.028 \\
\hline & Rural (ref) & & & & & & \\
\hline \multirow[t]{5}{*}{ Wealth status } & Richest (ref) & & & & & & \\
\hline & Poorest & 1.802 & $0.915-3.547$ & 0.088 & 1.218 & $0.810-1.832$ & 0.343 \\
\hline & Poor & 1.083 & $0.538-2.179$ & 0.824 & 1.227 & $0.833-1.808$ & 0.300 \\
\hline & Middle & 1.521 & $0.784-2.951$ & 0.215 & 1.363 & 0.944-1.968 & 0.099 \\
\hline & Rich & 0.576 & $0.286-1.160$ & 0.122 & 1.285 & $0.926-1.782$ & 0.134 \\
\hline \multirow{4}{*}{$\begin{array}{l}\text { Mothers } \\
\text { education }\end{array}$} & Higher (ref) & & & & & & \\
\hline & No education & 0.826 & $0.385-1.73$ & & 0.870 & $0.545-1.387$ & 0.558 \\
\hline & Primary & 0.680 & $0.348-1.328$ & & 0.834 & $0.585-1.189$ & 0.315 \\
\hline & Secondary & 0.801 & $0.409-1.569$ & & 0.592 & $0.410-0.854$ & 0.005 \\
\hline \multirow[t]{3}{*}{$\begin{array}{l}\text { Age at first } \\
\text { birth }\end{array}$} & $\begin{array}{l}\begin{array}{l}30-39 \\
\text { (ref) }\end{array} \text { years } \\
\end{array}$ & & & & & & \\
\hline & $\begin{array}{l}\text { Below } \\
\text { years }\end{array}$ & 0.159 & $0.062-0.405$ & $0.000 *$ & 0.458 & $0.241-0.869$ & 0.017 \\
\hline & $20-29$ years & 0.257 & $0.103-0.638$ & 0.003 & 0.648 & $0.347-1.212$ & 0.174 \\
\hline \multicolumn{8}{|l|}{$\begin{array}{l}\text { Maternal } \\
\text { characteristics }\end{array}$} \\
\hline \multirow{5}{*}{$\begin{array}{l}\text { BMI } \\
\text { Birth spacing } \\
\text { (preceding } \\
\text { birth interval) }\end{array}$} & $\begin{array}{l}\text { Overweight(re } \\
\text { f) }\end{array}$ & & & & & & \\
\hline & Underweight & 0.435 & $0.215-0.881$ & 0.021 & 0.922 & $0.469-1.813$ & 0.814 \\
\hline & Normal weight & 0.736 & $0.497-1.090$ & 0.126 & 1.012 & $0.697-1.468$ & 0.951 \\
\hline & $>2$ years(ref) & & & & & & \\
\hline & $<2$ years & 1.938 & $1.358-2.768$ & 0.000 & 1.549 & $1.047-2.292$ & 0.028 \\
\hline \multicolumn{8}{|l|}{$\begin{array}{l}\text { Neonatal } \\
\text { characteristics }\end{array}$} \\
\hline \multirow[t]{2}{*}{ Birth Order } & First child & 1.775 & $0.775-1.782$ & 0.447 & 1.412 & $0.962-2.073$ & 0.08 \\
\hline & $\begin{array}{l}2^{\text {nd }} \text { or } 3^{\text {rd }} \text { child } \\
4^{\text {th }} \text { and above } \\
\text { (ref) }\end{array}$ & 1.104 & $0.773-1.576$ & 0.586 & 1.188 & $0.844-1.63$ & 0.323 \\
\hline \multirow[t]{5}{*}{ Size of the child } & $\begin{array}{l}\text { Very } \quad \text { large } \\
\text { (Ref) }\end{array}$ & & & & & & \\
\hline & $\begin{array}{l}\text { Larger than } \\
\text { average }\end{array}$ & 1.344 & $0.600-3.012$ & 0.472 & 0.941 & $0.452-1.958$ & 0.870 \\
\hline & Average & 0.965 & $0.434-2.146$ & 0.931 & 0.446 & $0.215-0.929$ & 0.031 \\
\hline & $\begin{array}{l}\text { Smaller than } \\
\text { average }\end{array}$ & 1.027 & $0.424-2.487$ & 0.952 & 1.116 & $0.507-2.452$ & 0.786 \\
\hline & Very small & 2.015 & $0.757-5.362$ & 0.160 & 1.523 & $0.634-3.660$ & 0.347 \\
\hline \multirow[t]{2}{*}{ Sex of the child } & Female (ref) & & & & & & \\
\hline & Male & 1.423 & $1.038-1.950$ & 0.028 & 1.443 & $1.077-1.943$ & 0.014 \\
\hline \multirow[t]{4}{*}{ Birth weight } & $\begin{array}{l}\text { Above normal } \\
\text { birth } \\
\text { weight(ref) }\end{array}$ & & & & & & \\
\hline & $\begin{array}{l}\text { Not weighed at } \\
\text { birth }\end{array}$ & 1.933 & $1.184-3.158$ & 0.008 & 2.584 & $1.716-3.891$ & 0.000 \\
\hline & $\begin{array}{l}\text { Low birth } \\
\text { weight }\end{array}$ & 6.677 & $\begin{array}{l}3.200- \\
13.936\end{array}$ & 0.000 & 2.354 & $1.255-4.415$ & 0.008 \\
\hline & $\begin{array}{l}\text { Normal birth } \\
\text { weight }\end{array}$ & 1.374 & $0.777-2.431$ & 0.275 & 0.799 & $0.485-1.314$ & 0.377 \\
\hline
\end{tabular}


KDHS 2008 09

\begin{tabular}{|c|c|c|c|c|c|c|c|}
\hline \multicolumn{8}{|l|}{$\begin{array}{l}\text { Health care } \\
\text { characteristics }\end{array}$} \\
\hline \multirow{2}{*}{$\begin{array}{ll}\text { Place } & \text { o } \\
\text { delivery } & \end{array}$} & Facility(ref) & & & & & & \\
\hline & Home & 0.843 & $0.542-1.311$ & 0.448 & 0.782 & $0.572-1.068$ & 0.122 \\
\hline \multirow{3}{*}{$\begin{array}{l}\text { Number } \\
\text { ANC visits }\end{array}$} & $>4$ ANC visits & & & & & & \\
\hline & No ANC visits & 0.523 & $0.215-1.272$ & 0.153 & 4.668 & $2.899-7.516$ & 0.000 \\
\hline & 0-3 ANC visit & 0.432 & $0.263-0.709$ & 0.432 & 1.572 & $1.164-2.125$ & 0.003 \\
\hline \multirow[t]{3}{*}{$\begin{array}{l}\text { Initiation of } \\
\text { breastfeeding }\end{array}$} & $\begin{array}{l}\text { Immediately(r } \\
\text { ef) }\end{array}$ & & & & & & \\
\hline & $\begin{array}{lr}\text { Between } & 1 \\
\text { hour and } & 24 \\
\text { hours }\end{array}$ & 2.768 & $1.353-5.662$ & 0.005 & 0.629 & $0.299-1.323$ & 0.222 \\
\hline & After 24 hours & & 0 & & 1.899 & $0.796-4.533$ & 0.148 \\
\hline
\end{tabular}

\section{Discussion}

Overall the aim of the study was to identify risk factors associated with neonatal mortality in Kenya comparing data from KDHS 2008 and KDHS 2014 using a nationally representative sample. This analysis showed that several factors were significantly associated with neonatal mortality after adjusting for confounding variables.

The analysis shows a decline in the neonatal mortality rates from 31 deaths per 100,000 to 23 deaths per 100,000 between 2008 and 2014. The decline in the neonatal mortality rates is an indicator towards the combined interventions by different sectors, including health and social awareness programs to support child survival. The analysis of the KDHS survey data showed that male children had a significantly higher risk of dying during the neonatal period compared to female neonates. This finding is consistent with other study findings which have had similar outcomes (Ezeh et al, 2014) who analyzed the determinants of neonatal mortality with evidence from the Nigeria demographic health survey under taken in 2008.

The findings also showed that mothers who perceived their neonates to be very small had a greater risk of dying in the first month compared to those who perceived their neonates as large. These findings are consistent with other similar studies in India and Asia have shown the same findings, it is important to note that the rationale for the perceived size of the child is subjective. However, birth size was an important proxy for birth weight considering than more than $50 \%$ of the neonates were not weighed at birth. Other studies have also shown correlation between birth size and actual birth weight. Low birth weight children had the greatest risk of dying within the first month of life. Neonates of mothers who had not attended any ante natal clinics were 4 times more likely to die in the first month of life compared to those whose mother attended ANC clinics. These findings are consistent to studies that have shown the protective role of ANC against neonatal mortality. In the meta-analysis of data across regions, Doku \& Neupane (2017), findings showed that ANC attendance was protective against neonatal mortality.

Early initiation of breast feeding was a significant determinant of neonatal survival. Neonates who were initiated to breastfeeding after one hour had their risk of death increase compared to initiate to breastfeeding breastfed immediately. These findings were similar to other studies and reviews that showed that early initiation to breastfeeding was associated with increased risk of neonatal mortality (Khan et al, 2015). There was a significant association between birth weight and neonatal deaths. Children with low birth weight in 2008 were 6 times more likely to die in the first month of life compared to normal weight children. This was also the case in the 2014 study. Infants of mother with less than 2 years spacing had a higher risk of dying compared to those born with more than 2 years spacing.

The findings in this study show that there are association between various demographic, maternal, neonatal and health related characteristics with neonatal mortality.

The strengths and weaknesses of this study need to be considered. This study is nationally representative and a multi stage cluster sampling. Additionally, recall errors arising from the dates of birth and death given by the women. One of the weaknesses of this study is that only surviving women were interviewed, therefore missing on other neonatal deaths that may have also occurred as a result of the death of the mothers. Other factors such as gestational age that are known to affect the neonatal survival were not assessed in this study. 


\section{Conclusions}

Analysis on the determinants of neonatal mortality show that sex of the child (being male), birth weight of the child, preceding birth interval living in urban areas and initiation of breast feeding were important determinants of neonatal mortality. In the $2008 \mathrm{KDHS}$, birth weight, birth spacing being male and initiation of breastfeeding one hour after birth. In the 2014 analysis, the most significant determinants of neonatal mortality include being born in the urban areas, children born with low both weight, children born less than 2 years after the previous birth and children whose mothers did not attend any ANC clinics and those who attended less than 4 clinic sessions.

Based on these findings, further social advocacy on the adoption of the recommended minimum of 4 ANC visits during pregnancy is imperative for expectant mother to enhance opportunities for care during pregnancy, improve nutrition support through supplementation of Iron and folic acid, nutrition education for dietary diversity and awareness creation on any danger signs during pregnancy. In addition, further sensitization on the need adopt appropriate family planning options by women should be scaled, so that they are able to make better decisions on when to have children after healing. This will go hand in hand in demystifying the misconceptions that are preventing uptake of contraceptive options among the women. At the community level, operationalization of the community level strategies especially through the community health front line workers to incentivize mothers to deliver their babies in health facilities especially in key in ensuring there is an increase in the number of expectant women delivering their babies under the supervision of a skilled health care provider.

Finally, there should be further strengthening of baby friendly hospital initiatives (BFHI) and complimenting it with the baby friendly community initiative (BFCI) will ensure that more women are initiating their infants on breast milk immediately after birth and continue to breastfeed exclusively for 6 months, to increase the survival of the neonates since breastfeeding exclusively and on demand has been identified among the high impact nutrition interventions that have improved neonatal outcomes.

\section{REFERENCES}

Ajaari M.H., Weiner R.A.SA., Owusu-Agyei S. (2012), "Impact of place of delivery on Neonatal mortality in Rural Tanzania", International Journal of MCH and AIDS. Vol (1):49-59.

Bhutta Z. A., Darmstadt G. L., Hasan B. S., Haws R A. (2005), "Community based interventions for improving perinatal and neonatal health outcomes in developing countries", A review of evidence Pediatrics 115: 519617

Black R. E., Allen R. H., Bhutta Z. A. Caufeld L. A. De Onis M., Mathers C. \& Rivera J. and maternal and child under nutrition study group. (2008), Maternal and child under nutrition.

Global and regional exposure and health consequences. Lancet 371: 5-22.

Brown C. A., Sohani S. B., Khan K., Lilford R. \&Mukhwana W. (2008). Antenatal care and perinatal outcomes in kwale District, Kenya. Biomedical central Pregnancy and childbirth. 8:2

Chaman R, Holakouie K, Golestan B, Nabavizade H Yunesian M. (2009). Neonatal mortality risk factors in rural parts of Iran: A nested Case control study. Iranian Journal of public health.

Chowdhury Q, Islam R. \& Hossain K. (2009). "Effects of health related factors on neonatal, post neonatal, infant and child mortality", Current research journal of biological sciences. 3:83-88.

Chowdhury Q. Islam R., \& Hossain K. (2010), "Socio economic determinants of neonatal, post neonatal and infant and child mortality", International Journal for Sociology and Anthropology, 26 (6). 118-125.

Dalollio L., DiGregori V., Lenzi J., Franchino G., Calugi S., Domenighetti G. \& Frantini M. P. (2012), "Socio economic factors associated with infant mortality in Italy", International Journal of equity in health. 11:45

Edmond M K., Zandoh C., Quigley M., Amenga E S. Owusu S \&, Kirkwood B., (2006), "Delayed breastfeeding initiation increases the risk of neonatal mortality", Pediatrics 117: 380-386.

Attar R. R., \& Kimani J. (2012), "Determinants of under-five mortality in rural and urban Kenya", The International Electronic Journal of Rural and Remote Research, Education, Practice and Policy. 1445.

Finlay J. E., Ozaltin E., Canning D. (2011), "The association of maternal age with infant mortality, child anthropometric failure, diarrhea and anemia for first births: Evidence from 55 low and middle income countries", Bio Medical Journal open. doi:10.1136.

Fort A, Kothari T M, Abderahim N. (2008), “Association between maternal birth, and neonatal characteristics and neonatal mortality in 5 Asian countries", DHS working papers. Measure DHS.

Goldenberg L. (2009), "Neonatal mortality, risk factors and causes: A prospective population based cohort study in urban Pakistan", Bulletin World Health Organization Vol 87:130-138

Hill K. \& Choi Y. (2006), "Neonatal mortality in the developing world", Demographic research 14: 429-452.

Jackobsen M, Sodemann M, Nylen G, Bale C, Nielsen J, Lisse I \&Aaby P. (2003), "Breastfeeding status as a predictor of mortality among refugee children in an emergency situation in Guinea Bissau", Tropical Medicine and International Health. Vol 8(11) 992-996.

Jehan I., Harris H., Salat S., Z eb A., Mobeen N., Pasha O., McCure E., Moore J., Wright J \& Goldenberg R.

(2008), "Neonatal mortality, Risk factors and causes: A prospective population based cohort study in urban 
Pakistan", Bulletin of the World Health Organization; 87:130-138

Khatun F., Rasheed S., Moran A. C., Aram A.A., Shomick S. M., Sultana M., Choudry N., Iqbal M., \&Bhuiya A. (2012). Causes of neonatal and maternal deaths in Dhaka slums: Implications of service delivery. BMC public health 12:84

Khan J., Vesel L., Bahl R. \& Martines J C. (2015), "Timing of breastfeeding initiation and exclusivity of breastfeeding during the first month of life: effects of neonatal mortality and morbidity-systemetic review and meta-analysis", Maternal and child health journal 19 468-479.

Kenya National Bureau of Statistics (KNBS) and ICF Macro. (2010), Kenya Demographic and Health Survey 2008 09. Calverton, Maryland: KNBS and ICF Macro.

Kenya National Bureau of Statistics (KNBS) and ICF Macro. (2003) Kenya Demographic and Health Survey 2003.Calverton, Maryland: KNBS and ICF Macro.

Kitui J., Lewis S., \&Davey G. (2013), "Factors influencing place of delivery for women in Kenya: an analysis of the Kenya Demographic Health Survey 2008/2009", Biomed Central pregnancy and child birth,13 (40).

Lawn J E., Cousens S. \& Zupan J. (2005), “4 million deaths When, where why”, Lancet 365: 891-899.

Lisonvaka S., Pare E., \& Joseph K. S. (2013), "Does advanced maternal age confer a survival advantage to infants born at an early gestation?", BMC Pregnancy and child birth, 13 (87)

Liu L, Johnson H, Cousens S, Perin J, Scott S, Lawn J, Rudan I, Campbel H, Cibulskis R, Li M, Mathers C \& Black R. (2012), "Global, regional and national causes of child mortality". The Lancet series.

Malqvist M. (2011), "Neonatal mortality and invisible and marginalized trauma", Global health action. 4: 5724

Mekonnen Y., Tensou B., Telake B. S., Degefie T., \& Bekele A. (2013), "Neonatal mortality in Ethiopia: Trends and determinants", Biomedl central public health,13.

Mosley H. W. \& Chen L. C. (1984), "An Analytical framework for study of child survival in developing countries" Population and development review, 10. 25-45

Muldoon K. A., Galway L. P., Nakajima M., Kanters S., Hogg R. S., Bendavid E., \& Mills E. (2011), Globalization and health, 7 (42).

Mustafa H. E., \& Odimwegu C. (2008), "Socio economic determinants of infant mortality in Kenya: Analysis of KDHS 2003”, Journal of Humanities and Social Sciences, 2 (2).

Nathan R., Mwanyangala A M. (2012). Survival of neonates in rural southern Tanzania: Does place of delivery or continuum of care matter? Bio Medical Central pregnancy and child birth; 12:18.

Nisar B. Y., \& Dibley M. J. (2014), "Determinants of neonatal mortality in Pakistan: Secondary analysis of Pakistan".

Demographic Health Survey 2006-07. Biomedical Central Public health, 14:663

Nautili E. B. H., Chaouachi S., Said A. B., \& Marrakchi Z. (2010), "Determinants of neonatal mortality in Tunisian population", La Tunisie Medicale, 88, 45-45

Ribeiro A, Guimaraes M, Lima M, Sarinho S, Coutinho S. (2009), "Risk factors of neonatal mortality among children with low birth weight", Rev saude publica. 43.

Sharma D., Katz J., Mullany L. C., Khatry S. K., LeClerq S. C., Shrestha S. R., Darmstadt G. L., \& Tielsch J. M., (2008), "Young maternal age and the risk of neonatal mortality in rural Nepal" Archives of pediatric adolescent medicine Journal. 162(9): 828-835.

Smith K. L., Draper S. E., \& Mankotetelow. (2009), "Socioeconomic inequalities in survival and provision of neonatal care: Population based study for very preterm infants", British Medical Journal,339.

Titaley C, Dibley M J, Agho K., Roberts C L \& Hall J. (2009), "Determinants of neonatal mortality in Indonesia", Biomed central Public health, 8.

Titaley C., Dibley M. J, Roberts C. L., Hall J., \& Agho K. (2009), "Iron and folic acid supplements and reduced early neonatal deaths in Indonesia", Bulletin of the World Health Organization, 88:500-508.

Tachiweyika E., Gombe N., Shambira G., Chadambuka A., Tshimanga M., \& Simukai Z. (2009), "Determinants of perinatal mortality in Marodera district, Mashona Land East Province of Zimbabwe, 2011: A case Control study", Pan African Medical journal.

Tura G., Fantahun M. \&Worku A. (2013), "The effect of health facility delivery on neonatal mortality: Systematic review and meta-analysis", Biomedical Central pregnancy and child birth,13:18.

UNICEF., (2011), "Levels and trends in child mortality report", UNICEF.

UNICEF. (2009), "State of the world's children 2009", New York. UNICEF

WHO, (2011), "World Health Statistics 2011".

Zanini R.R., Braganca de morales A. Giugliani E R J \& Riboldi J., (2011), “Contextual determinants of neonatal mortality using two analysis methods", Rio de grande do sul Brazil. Rev saude publica. Vol 45. 